\title{
Marloes de Valk
}

\section{REFUSING THE BURDEN OF COMPUTATION: EDGE COMPUTING AND SUSTAINABLE ICT}

\begin{abstract}
This paper asks what we can learn from edge computing about the commitment of Big Tech to diminish its ecological footprint. The text starts with the COVID-19 pandemic being framed as opportunity for more sustainability and unpacks edge computing as one of the elements proposed as a solution, next to working from home. It interrogates the discourse behind these solutions, one of technological fixes that allow 'business as usual' to continue, undisturbed by government regulations, outsourcing the burden of environmental responsibility to citizens. The paper draws parallels between edge computing, Big Tech's approach to sustainability and the history of the Sustainable ICT discourse and proposes that to truly diminish ICT's footprint, a refusal of the burden of computation and digital enclosure (vendor lock-in) is needed, by collectively building and financing network services.
\end{abstract}

APRJA Volume 10, Issue 1, 2021

ISSN 2245-7755

CC license: 'Attribution-NonCommercial-ShareAlike’. 


\section{Introduction}

This paper asks what we can learn from edge computing, moving computation closer to the end-node in a network, about the commitment of Big Tech to diminish its ecological footprint. It is written as part of the workshop Research Refusal at Transmediale 2021/2022. The workshop focussed on how academic autonomy can be preserved in the context of capitalist tech development, in the present pandemic context of online delivery and the need for alternatives to corporate platforms. Inspired by the festival's mention of small acts of refusal residing in everyday practices and forms of resistance that allow a repair of collective infrastructures, I decided to start with the everyday practices I was now confronted with, back-to-back video calls, and unpack one seemingly small element of this to find out, as the workshop set out to discover, what might be refused, and in what ways.

My question about edge computing stems from a small incident this winter. I was invited to participate in an online event and was asked to use the organisations background image in the video conferencing software Zoom. I installed Zoom on Linux and tried to make the background image work, but failed. While Linux runs neatly on my old hardware, the Zoom documentation page about Virtual backgrounds taught me my processor is too old. Video conferencing tools handle background image calculations on the client-side, to reduce network traffic and latency. My laptop can hardly handle video conferencing without augmentation, client-side calculations were well out of its league. Using hardware as long as possible is the simplest way to reduce the environmental impact of technology, the second easiest way is to not be wasteful with CPU cycles, which is why I decided to refuse the upgrade-or-die mandate and participated in the event with a messy office as backdrop.

This paper starts with a small act of refusal, rejecting heavy client-side computation, edge computing, during video conferencing calls, and ends with a refusal of vendor lock-in, a form of digital enclosure. It places this relatively recent development in network infrastructure in the context of our current ecological crisis, manifesting itself as climate change, a loss of biodiversity known as the $6^{\text {th }}$ extinction and of course the COVID-19 pandemic. It asks what we can learn from edge computing about the commitment of Big Tech to diminish its ecological footprint by first diving into edge computing itself: what is it, why is it needed and what are its ecological consequences? The second part of the text compares this to the tech industry's green promises. To find out if the tech industry's interpretation of sustainability matches larger societal trends, the text reviews the history of Sustainable ICT discourse. I will finish with a refusal to believe in the fairy tale of self-regulation, combined with a refusal of digital enclosure, the burden of computation and individual responsibility for systemic problems.

\section{Edge computing}

The Corona pandemic makes current unsustainable practices painfully clear. According to the 2020 UN Intergovernmental Platform on Biodiversity and Ecosystem Services (IPBES) Workshop Report on Biodiversity and Pandemics (2-3) the exponential rise in consumption and trade in commodities such as meat, palm oil and metals, largely by developed nations, is one of the main drivers of the destruction of biodiversity, which in turn is the main trigger to a new era of pandemics. The main cause of climate 
change, the destruction of biodiversity, this and future pandemics, are one and the same: overconsumption by the Global North. The report is not afraid to criticise current pandemic strategies, only responding after a new disease appears instead of preventing its emergence. It speaks of the inequality between the Global North and South: "[p]andemics are driven largely by unsustainable consumption of richer developed and emerging countries, but their impacts are particularly felt by the Indigenous Peoples, and those living in poverty who cannot afford to avoid work to social distance" (40) but because of its focus on overconsumption, it places the blame with consumers, not producers, and avoids the larger political question about what drives this overconsumption and inequality. Even though the report mentions that the reduced oil consumption due to the lockdowns are likely temporary and insignificant in the long term, it seems some businesses still frame the pandemic as an opportunity for sustainability.

A lockdown meant working from home when possible, drastically decreasing air and car travel. Remote work became the emblem of sustainable working: less travelling meant less $\mathrm{CO}^{2}$, nitrogen oxide, carbon monoxide, and other polluting emissions. This temporary clearing of the air was made possible by the uptake of video conferencing and the goodwill of all those subjected to it. Platforms such as Microsoft Teams, Skype, Zoom and Google Meet embraced the explosion in demand. Overall Internet traffic volume increased with 15-20\%, applications for remote working and education even saw increases beyond $200 \%$. During the first lockdown, while network service providers were still busy upgrading the capacity of network bottlenecks, glitchy video streams and malfunctioning educational platforms were of the order of the day. Overall Internet infrastructure was able to handle the rapid

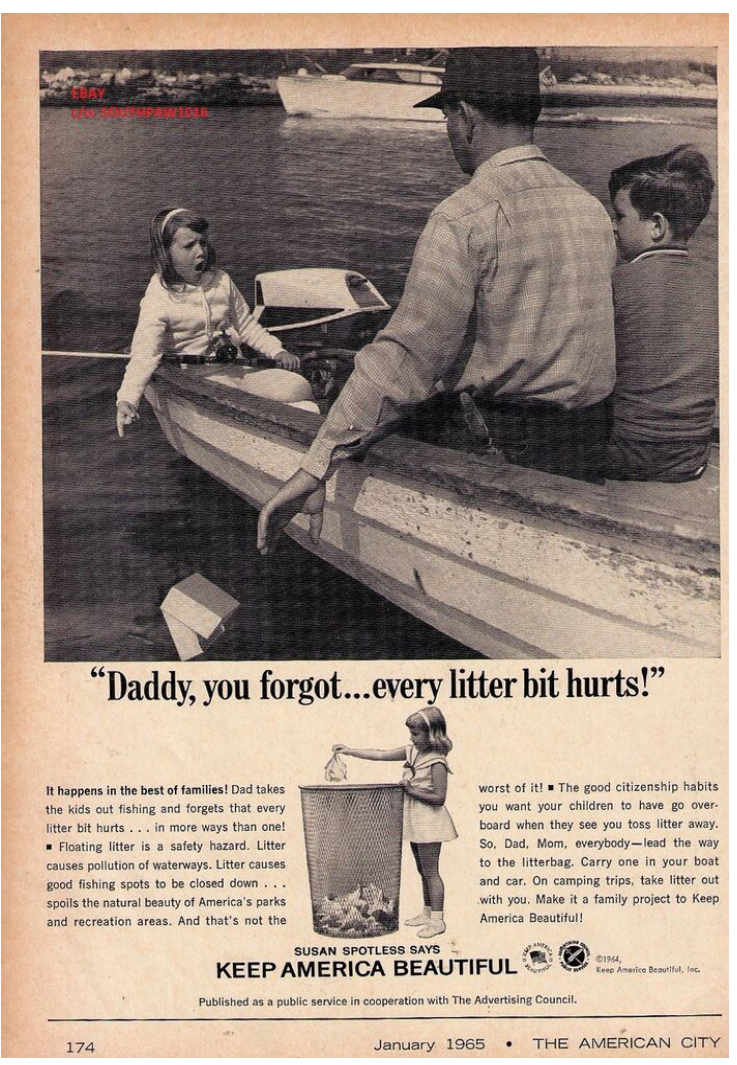

Figure 1: A 1965 Keep America Beautiful advertisement featuring Suzy Spotless saying: "Daddy, you forgot... every litter bit hurts!”; Keep America Beautiful, Inc. and Advertising Council. Photograph. The American City, January 1965, Ebay, https://i.ebayimg.com/ images/i/352723715470-0-1/s-11000.jpg.

increase well though, due to its distributed nature (Feldmann et al. 13).

Video conferencing platforms reduce network traffic and latency by offloading certain computational tasks to the client, or a node close to them. These client-side calculations are called 'edge computing'. The edge is the entry point to, or endpoint of, the network, depending on your perspective. On the edge are smartphones, laptops, PCs and a rapidly growing mountain of Internet of Things (loT) devices, such as coffeemakers, smart city surveillance equipment and selfdriving cars. Video conferencing software makes use of edge computing for the calculation of the background image, and blur, some platforms allow users to set. While a user is 
streaming video and moving about in front of their camera, their computer is continuously calculating which pixels are background and which are foreground, in order to replace the background with an image of the user's choosing. Performing these calculations in the cloud would be too slow, and the extra data transmitted would congest the network at the point where it has the smallest capacity: the last mile.

It is an industry trend to shift network bottlenecks into local computational tasks. It is not a new method, it started in the 90s with the advent of Content Delivery Networks (CDN) for a faster distribution of video to end users. Today data storage and computational tasks are both offloaded to, or close to, the edge node in order to improve latency and reduce network traffic. It is particularly helpful for tasks that require fast processing speed, such as video conference backgrounds, facial recognition and augmented reality, but also for bandwidth heavy applications such as cloud gaming and the growing pile of smart objects on the edge of networks, that are constantly phoning home to corporate servers generating massive amounts of data to be processed, real-time data generated by sensors and users, with zero tolerance for latency. After all these years of centralisation through Software as a Service and cloud storage, when software and data were moved from personal computers or small office servers onto centralised, corporate servers many hops away, some of that is once again decentralised, but not without a tight, centralised grip on the top layer, which remains in the stronghold of the network's core data centres.

This decentralisation is of a very particular kind and is connected to the rolling out of several new infrastructures. Edge computing is often combined with Machine Learning (ML) because the massive amount of multimodal data (i.e., video and audio) that is constantly being sensed by loT devices, needs the rapid processing that $\mathrm{ML}$ can provide (Zhou et al. 1742-1743). Not only is $M L$ very resource intensive, it requires edge devices to be equipped with some form of $\mathrm{Al}$ accelerator. This has two consequences: an increase in electricity consumption and an explosion of newly produced devices, and consequently e-waste, because older end-node devices aren't compatible with services using ML. In certain loT settings, edge computing means micro data centres are required in between end-nodes and data centres, to decrease latency for devices that are too resource constrained to perform heavy computation on large datasets themselves. These 'data centres in a box', similar to the previous example, mean another increase in electricity consumption and newly produced hardware.

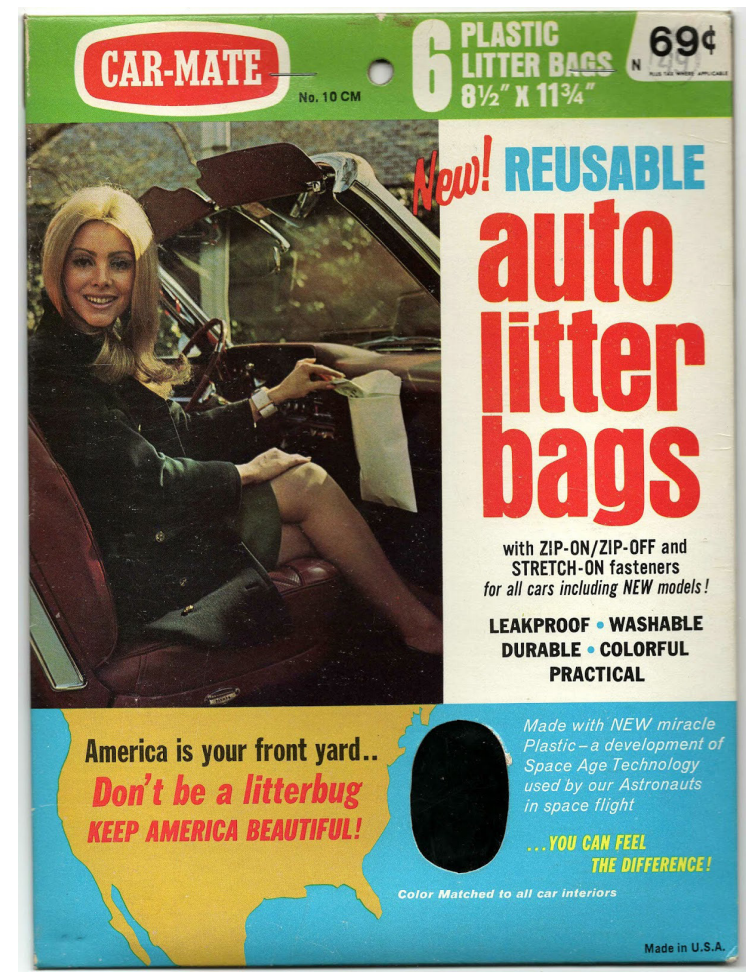

Figure 2: A photo of CAR-MATE plastic litter bags, meant to stop plastic littering, with slogans from the Keep America Beautiful campaign; Otto, Chris. May 27 2018, Papergreat, http://www.papergreat.com/2019/05/ keeping-america-beautiful-with-new.html 
The rolling out of $5 \mathrm{G}$ cellular networks is also linked to this development. At the moment of writing, it is mostly targeted at mobile broadband for handheld devices, which roughly translates to watching videos or playing games while on the road. It offers the transfer speed needed for businesses to use edge computing, without needing to rethink their centralized core infrastructure. $5 G$ is also rolled out to accommodate the growing IoT, even though this is based on predictions rather than current needs. As mentioned earlier, the enormous amount of devices constantly communicating to servers require more bandwidth. A self-driving car for example, requires edge computing to decide to hit the brakes on time, and with industry's plans to have an increasing number of them on the road, high bandwidth is needed for the communication of more latency tolerant data to the cloud. As more and more mobile devices are coming online, mobile bandwidth needs to keep up with this development. $5 G$ is notoriously energy inefficient though. According to Earl McCune, professor in the Electronic Circuits and Architectures group at TU Delft, 2G had an energy efficiency of $60 \%$, "For $5 \mathrm{G}$, the efficiency will be only $10 \%$, meaning that [for every 10 watts] nine watts will be turned into heat" (Engelsman).

In the case of video conferencing, edge computing means non-optimized hardware is doing the heavy lifting, which is not energy efficient. Something most users notice when their computers start to heat up and their fan starts making noise in an attempt to stay cool, in the worst cases failing and shutting down. In a nutshell, a user's phone and computer are performing computational tasks for Microsoft, Google, Zoom and others. Users are paying for the electricity and have to update their hardware if they want to make use of the services offered. Next to people assuming the cost for this increase in electricity use and hardware, there is the massive environmental impact these increases bring. Still these developments are described as part of an increase in sustainability, because they lower energy consumption at the core of the network, in data centres, completely ignoring the overall increase in energy use and hardware production required to roll out these services at the edge. Does corporate sustainability mean outsourcing the burden of computation to others?

\section{Sustainable Big Tech?}

To assess the commitment of Big Tech to reduce their environmental impact, I'd like to briefly review the promises that are made. The overall argument against Google, Microsoft, Amazon and other cloud service providers being 'green' is of course that their business model is based on growth and stimulating consumption and thereby production, something mentioned at the start of the paper as the main cause of our current ecological crisis. But even if forgetting this argument for a moment, the business practices powering the business model are worth having a closer look at. I will briefly review Google's sustainability promises and practices to unpack in concrete terms what their sustainable promises are based on. I will focus on Google because it is claiming to be the cleanest cloud in the industry, so if there are plot holes in its sustainability narrative besides the gaping one of being in the advertising business, it doesn't bode well for those clouds of a lesser green.

Google's most pertinent claims are twofold: operating $100 \%$ on renewable energy ("Google Environmental Report 2020" 3) and wanting to "disrupt the waste economy" by maximising product use and reuse (" $\mathrm{A}$ Circular Google" 2). The renewable energy claim is truthful depending on how you 


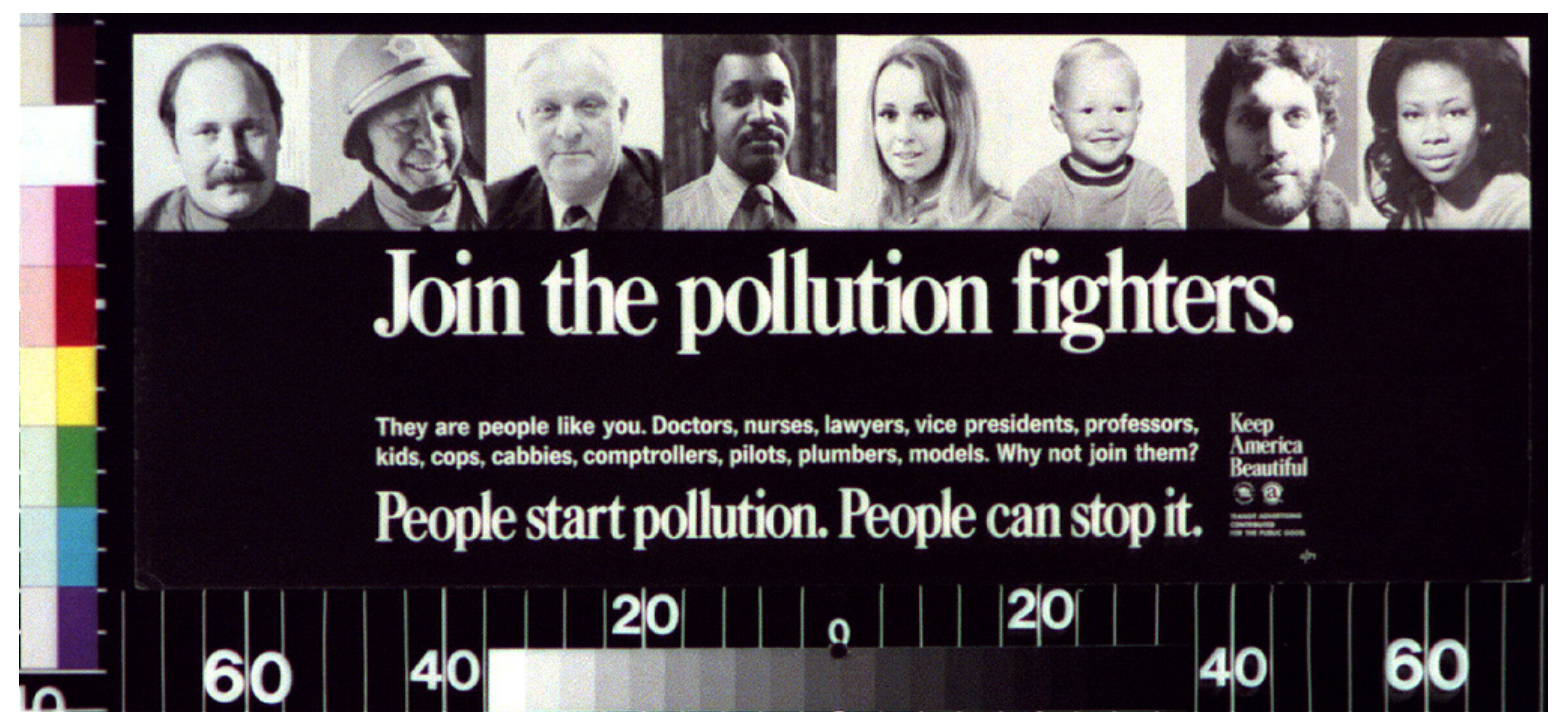

Figure 3: A 1971 Public Service Announcement by Keep America Beautiful, emphasizing individual guilt and responsibility; Keep America Beautiful, Inc. and Advertising Council. Join the Pollution Fighters. Library of Congress, 1971, www.loc.gov/ item/2016649872/.

define the scope of a company's operation. Besides, whether the way Google acquires its renewable energy is of benefit to society is also questionable. Google powers its data centres and offices with renewable energy, but stopped its own renewable energy R\&D project $R E<C$ in 2011 because " $R E<C$ would not be able to deliver a technology that could compete economically with coal" (Koningstein and Fork). Only four years after its launch November 2007, Google researchers came to the conclusion that more disruptive energy innovations were needed in order to stop climate change, which would require more investments into R\&D, but from others, not from Google. If a corporation with a 2020 revenue of 181.69 billion dollar cannot invest, who can?

Today Google places its data centres in the vicinity of, for instance, a windfarm and purchases its energy there. In Eemshaven, the Netherlands, Google constructed a hyperscale data centre and made a deal with a local energy provider to purchase all of the energy produced by a local windfarm. Microsoft did something similar when building a datacenter in Hollands Kroon, purchasing all energy produced by a local windfarm for 10 years. According to the provider, Nuon, the energy could power 370.000 households. These windfarms have received subsidies by the Dutch government with the goal of achieving green energy and emission targets, but because they end up solely covering the energy demand of newly constructed data centres, representing additional instead of existing energy use, no progress is made and taxpayers are indirectly sponsoring Google's green public image.

In Ireland, another popular destination for the construction of new data centres, Eirgrid reports that by 2027 , electricity demand from data centres will have risen to $31 \%$ of total demand, with the expansion and development of Ireland's public transmission network being shaped by the intensive energy demands of data centres, aided by state legislation and planning (Bresnihan and Brody). In the Netherlands the energy providers cannot keep up with the demand for renewable energy by data centres. To accommodate the data centres, the Dutch government, together with energy providers and market parties, propose using the 
national climate agreement to change the legal framework to shorten the time to realise a new connection to the grid (Weerwind, Frank and Steenbakkers 23). The energy demands of data centres is not only accepted as a given, rules are bend, laws are adjusted, just to accommodate them, whereas citizens are expected to pay their taxes and install smart meters in their homes to lower their energy use.

Next to the gobbling up of subsidised renewable energy projects, the $100 \%$ carbon neutral claim only covers Google's data centres and offices, not the energy use caused by their products as soon as the data packets have left the data centre (Lin et. al.). Google has built 21 hyperscale data centres around the globe, but in order to bring data closer to high traffic areas, it uses smaller Edge Points of Presence (PoP) data centres. For popular, high-bandwidth content such as video, the latency would still be too much, so even smaller data centres, the Google Global Cache, making use of third-party Content Delivery Networks (CDN), hosts content that is in high demand. PoP's and CDN's aren't owned by Google, they only host its equipment, and aren't covered by the carbon neutrality claim, which only concerns networking infrastructure under Google's direct operational control, as can be learned from an Ernst \& Young accountants' review report from 2019 (2). Google's sustainability report (80) mentions only business travel and employee commuting are compensated in the GHG protocol scope 3 category of down- and upstream emissions. From the $12,529,953$ tCO2e total 2019 emissions it is unclear what Google has included in the scope 3 "other" emissions, since these have not been independently reviewed. The main point is that even based on Google's own, unreviewed reporting, only $46 \%$ of total emissions were reduced and neutralised (ibid.).
The previous assessment is based on Google's own reporting. Independent research has varying outcomes, none as optimistic as Google's carbon neutral claims. According to a 2016 study, a life-cycle assessment of YouTube's delivery and viewing, Google only compensates between $1 \%$ and $5 \%$ of total YouTube energy use (Preist et al. 8). A more general study on ICT's energy use from 2017 estimated data centres to account for $45 \%$ of total ICT energy use (Belkhir and Elmeligi 457). The difference between the two studies can be explained by the fact that the latter also takes energy use in the production phase of a computer or server into account, which boosts the percentage of data centres, filled to the brim with regularly renewed hardware. Besides, YouTube is serving content using a lot of bandwidth and caches popular video material at CDNs which makes it much heavier on third party network infrastructure. In either case, whether its $2 \%$ or $45 \%$, independent reports conclude Google's services are nowhere close to being powered by $100 \%$ renewable energy.

The public's perception of Google as a green company is very important to its brand value. In a 2020 report by Alphabet for the Carbon Disclosure Project (CDP) the loss of this perception is mentioned as the second risk climate change indirectly poses to Google, potentially resulting in decreased revenues due to reduced demand for products and services (9). Google deems this risk "about as likely as not" to materialise. The third risk mentioned, is a change in customer behaviour due to changes in socio-economic conditions (10). If climate change results in people living in more precarious conditions, they will buy less and advertisers will stop using their services. Google optimistically deems this risk "unlikely" to materialise. The report also includes opportunities that climate change might bring. One opportunity that Google deems "virtually certain" is that their 


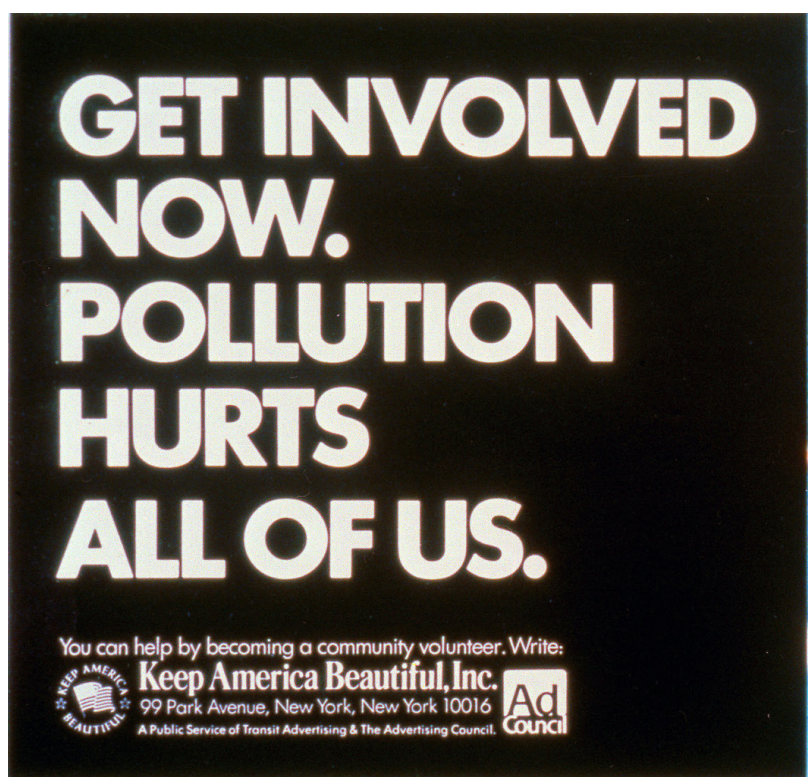

Figure 4: A 1971 Public Service Announcement by Keep America Beautiful, showing the face of American actor Espera Oscar de Corti, of Italian descent, portraying a weeping Native American; Keep America Beautiful, Inc. and Advertising Council. 1971, Milwaukee Sentinel, http://archive.jsonline.com/entertainment/books/ creators-of-smokey-the-bear-mcgruff-explored-in-newbook-b9992362z1-223654631.html

investment in Google Earth and other products associated with sustainability, will result in increased brand loyalty and an associated increase in revenue. Another opportunity, rated "very likely" to materialise is Google's returns on investment in downstream lowemission technology (16). The return on investment is confidential but Google hopes to profit while generating just enough energy to manufacture Google consumer products in the near future. Nowhere in the report is it mentioned that overconsumption, stimulated through advertisement (which makes up $84 \%$ of Google's revenue), is one of the key drivers of environmental collapse. Google is itself a risk factor to climate change, but as long as it can maintain its green reputation, it can profit from its sustainable image and increased demand for renewable energy. Google is not a risk to its own bottom line, not until consumer capitalism crumbles under the pressures of climate disaster.

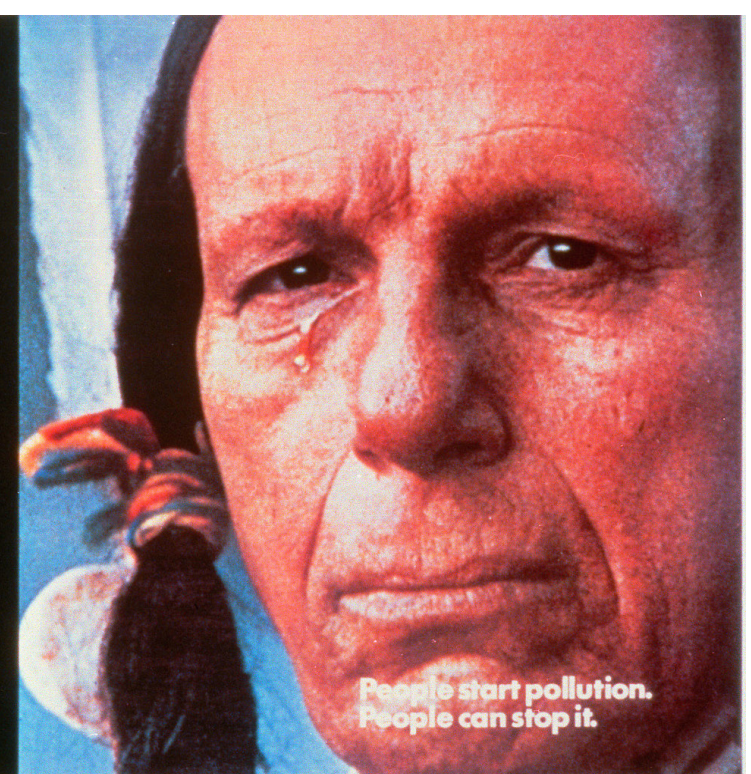

The second claim l'd like to briefly examine is Google's promise to "disrupt the waste economy" by maximising use and reuse of products ("A Circular Google" 2). According to an anonymous source, this reuse consists mainly of reusing metal rack cabinets. The convenient switch from percentages to units in their overview of waste diversion from their 2020 Environmental Report supports this suggestion (75). The 'landfill diversion rate' from the same report concerns "waste diverted to a more sustainable pathway than landfill or incineration without energy recovery" (“Google Environmental Report 2020" 75), meaning in $202090 \%$ of data centre waste could still have been incinerated, albeit with energy recovery. That same year, only $19 \%$ of components used for machine upgrades were refurbished inventory and while the report mentions 9.9 million components having been resold into the secondary market that year, there is no mention of a percentage, so I can only guess that my anonymous source could very well be right. Last but not least, Google uses custom hardware for all their servers and consumer products, meaning it cannot be reused by third parties. An example is their edge TPU, a custom build integrated circuit to run accelerated $\mathrm{ML}$ at 
the edge. Their statement about needing to disrupt the waste economy is only a promise at best.

To conclude, even the greenest cloud in the industry is not that green, and is mostly concerned with a sustainable appearance as competitive edge, not with becoming a truly sustainable business. Changing appearances while maintaining the existing polluting and damaging practices is the hallmark of greenwashing. The 2020 Greenpeace report Oil in the Cloud: How Tech Companies are Helping Big Oil Profit from Climate Destruction captures this nicely by outlining how Google, Microsoft and Amazon all have connections to some of the world's dirtiest oil companies for the explicit purpose of getting more oil and gas out of the ground and onto the market faster and cheaper. All three companies are aware of how this looks and have updated their websites to target the energy, rather than oil and gas sector. In May 2020 Google announced to no longer take on new contracts but will continue to work with existing ones: Chevron, Total, Schlumberger and Cognite + Aker BP. Amazon and Microsoft have made no such promises and while announcing optimistic carbon neutral, or even carbon negative goals, continue to make it easier for oil companies to find and produce oil. Is this approach to sustainability unique to Google, or part of a larger trend?

\section{Sustainable ICT}

Green ICT is the practice of environmentally sustainable computing. It is a broad and rather vague term that includes any practice reducing the impact of ICT in the production-, use- and end of life phase, as well as reducing the use of hazardous materials, repairability, and the recyclability or biodegradability of e-waste. It also encompasses the use of
ICT to make other sectors more sustainable. ICT, ethics and sustainability researchers Lennerfors, Fors and van Rooijen distinguish three historical phases in the development of Green ICT discourse: Green Computing, Green IT and Sustainable ICT (765). In order to understand current practices, it is important to briefly look at the history of this discourse based on the study of Lennerfors et al. The first phase, Green Computing, started the same year as the UN earth summit in Rio de Janeiro, in 1992, with the voluntary Energy Star labelling programme of the US Environmental Protection Agency. This phase focused on the sustainability of the ICT devices themselves, such as reducing the energy use of CRT monitors. The second phase, Green IT, kicked off in 2007 when the Gartner Institute released a white paper stating ICT used $2 \%$ of the UK's total energy consumption, about as much as the aviation industry (Mingay). A year earlier, Al Gore published his influential book $A n$ Inconvenient Truth. Next to that, the Kyoto Protocol, ratified by 192 parties in 1997, had set greenhouse gas emission goals with a commitment period starting in 2008. All these events led to increased public pressure on the tech industry to lower their environmental impact, leading to a wide adoption of Green IT practices. This phase is characterised by a shift in focus: ICT is no longer seen as the problem, but is promoted as part of the solution. Unsurprisingly this phase is not developed by environmental protection agencies, but by industry.

The reasoning behind the approach was that diminishing the impact of ICT itself would only have a small impact, whereas using ICT to make other sectors more sustainable was thought to have a major impact (Lennerfors et al. 213). This "greening by IT" instead of "greening of IT" would consist of providing 'smart' solutions such as route planning, web meetings, virtualisation of servers 


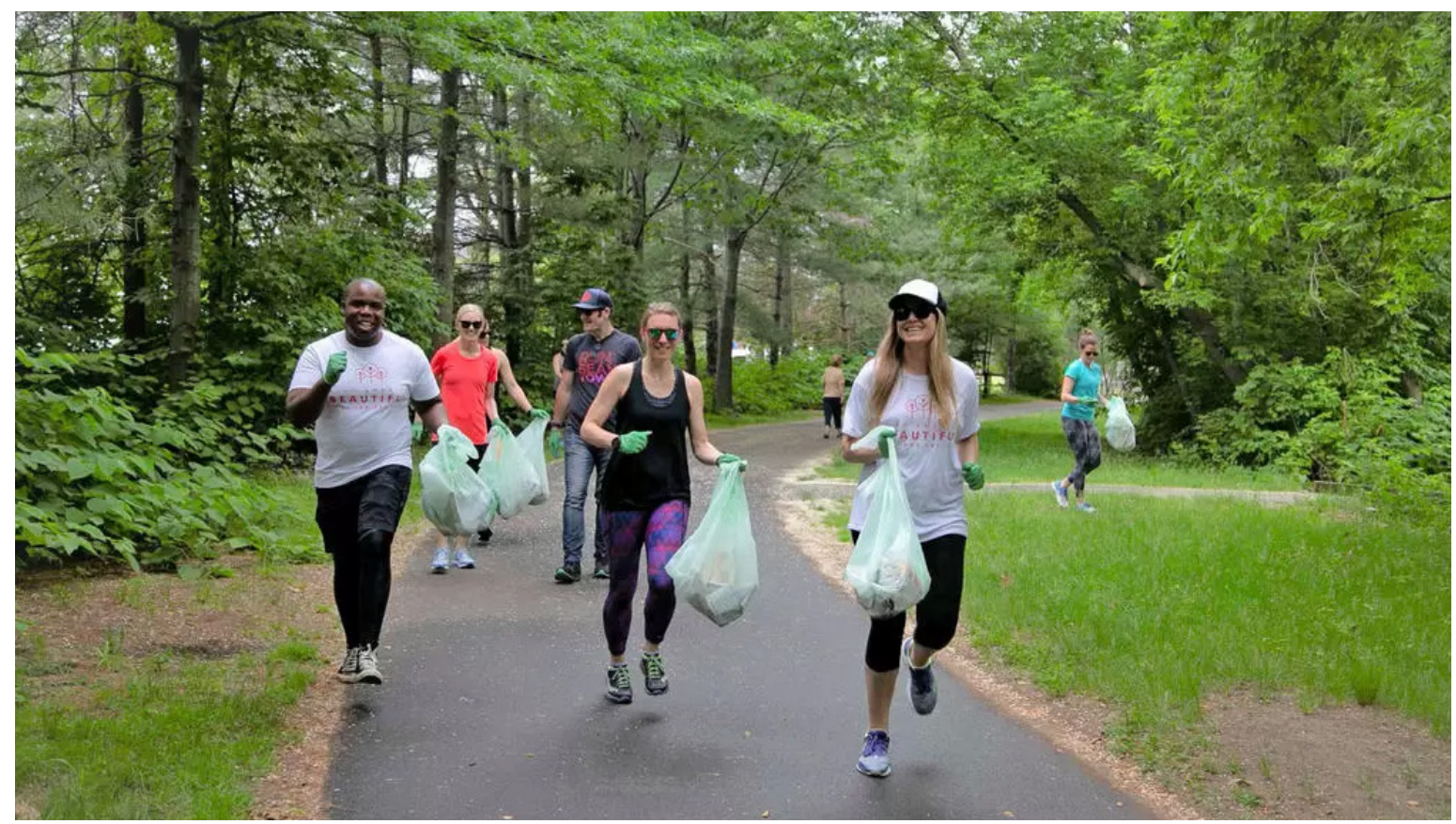

Figure 5: The Saucony and Keep America Beautiful Cleanup Run; Keep America Beautiful, Inc. June 2018, Keep America Beautiful, https://kab.org/ keep-america-beautiful-plogs-with-saucony/

and 'dematerialization'. The third phase, Sustainable ICT, shifts its focus even more, emphasising the potential of ICT to not only improve sustainability, but also economic and societal issues in the countries that can afford this (ibid.). In practice this means other countries are burdened with the environmental footprint that the production of such ICT involves. There is no real distinction between Sustainable ICT and regular ICT practices. Green ICT can therefore be described as a business strategy used to gain a competitive advantage and its description matches Google, Amazon and Microsoft's 'sustainability' practices perfectly.

Green IT and sustainable ICT translate lowering the footprint of ICT to lowering the electricity bill and nothing more. As the 2009 Global Action Plan Green ICT Handbook reads "BEING SUSTAINABLE SAVES MONEY (nothing is greener than the dollar!)" (5). The report mentions that in 2008, wholesale energy prices increased by over
$60 \%$ compared to the previous year, concluding "there are real savings to be made and quick wins to be had". A similar reading of business practices related to Green IT is discussed by Majima et al. in Green IT Did Not Take Place. The authors describe how Japanese businesses approached Green IT as the rebranding of power saving strategies they were already practising (89). Fors and Lennerfors analyse the case of a Swedish IT company that, right after the mid 1970's oil crisis, build a heat recovery system into their 1978 data centre to save money. The company started to reinterpret its past at the moment Green IT started trending, reimagining their heat recovery system as Green IT. This reinterpretation of economic motives led to a rapid transition from regular business to sustainability leader (13). There is of course nothing wrong with reducing emissions while saving money, except if this means nothing else is done to make a business more sustainable and if efforts are only made when energy prices rise, such as in 2008. Or worse, if this means sustainability efforts are dropped as soon as energy prices drop. Amazon for example, finally committed to a 


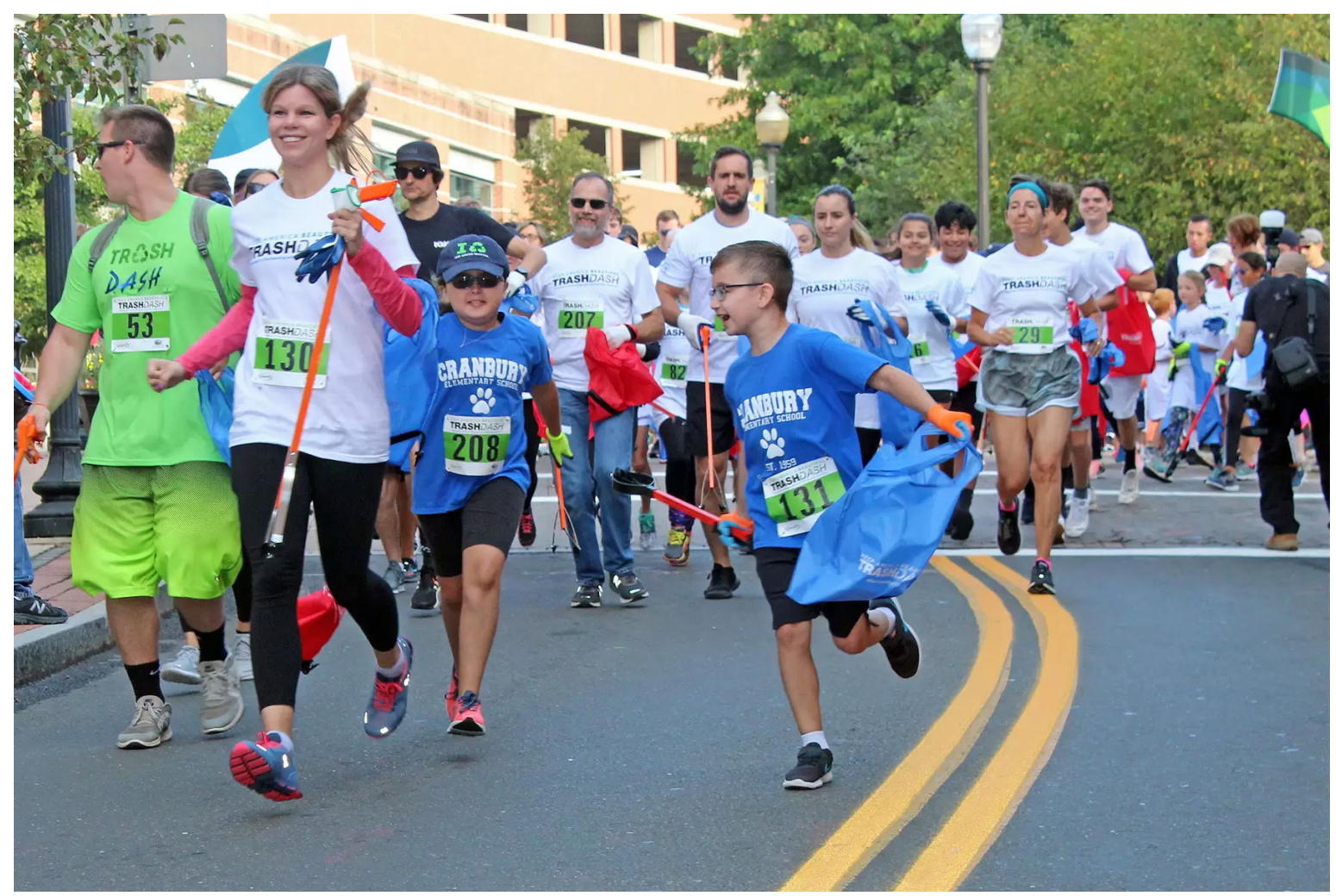

Figure 6: The start of the 2020 Trash Dash, a plogging fun run; Keep America Beautiful, Inc., 2020, Keep America Beautiful, https://kab.org/kab-events/ trashdash/event/

$100 \%$ renewable energy goal in late 2014 under public pressure. Yet, since then, it has expanded its data centre operations, but stopped all renewable energy investments after the 2016 wholesale electricity price dropped (Cook and Jardim 4).

It is beyond the scope of this paper to perform an in-depth analysis of green or 'natural' capitalism, but some relevant parallels between Sustainable ICT and green capitalism can be drawn. Natural capitalism, as coined by Paul Hawken, Amory and Hunter Lovins in 1999, aims at resolving the ecological crisis by 'fixing' industrial capitalism by internalising externalities: incorporating 'natural capital' and pollution into the cost of commodities, rendering ecological responsibility profitable. Nature becomes part of capital, so climate change can now be approached as an accounting problem. In both Sustainable ICT and natural capitalism, businesses are shaping the discourse and both obscure the relationships between climate change, endless economic growth and overconsumption. Both do not challenge the unsustainable 'business as usual' of capitalism, on the contrary, both view the ecological crisis as a market failure, and capitalism's market system as the best and quickest way to deal with the crisis, a technical problem with many profitable solutions (Klein 210, Wright and Nyberg 113). Self-regulation and voluntary reporting, such as the Carbon Disclosure Project, are supposed to make sure no slow political processes stand in the way of efficient environmental action and, win-win, profits. Both seem to be targeted at convincing policy makers as well as the public that no government regulations are needed to stave off climate change. The market has got us covered. Better still, the process is democratised because not only is ecological responsibility now shared with the consumer, who can excise their power by consuming 
ethical products, instead of consuming less; citizens indirectly subsidise the renewable energy of corporations through government subsidies and corporations shift more and more of their computation (and offices) away from their own data centres (and offices), to those on the edge of networks.

\section{Conclusion}

It seems I am living on the edge - edge working, edge computing, both promising a lower carbon footprint. On closer inspection it only lowers corporations' footprint, overall energy use increases. First, I was told that the cloud was more green, because it is powered by renewable energy, and far more efficient than my old hardware. Software as a Service has made many people move their software and data from personal computers to the cloud, now caught in a digital enclosure, locked in. When I'm in a video conference and my laptop is sucking dry the power grid to be able to keep up with the conversation, I'm being told it's more efficient to use edge computing because it lessens network traffic. Infrastructural sprawl increases and total energy consumption is going up either way. My energy provider installed a smart meter so I can gain insight into my usage and thus magically become more energy efficient. Climate change became my responsibility. Perhaps the smartness of the meter is its ability to distract from the urgent need to switch to renewable energy (Gabrys, 3-18)? It's yet another device on the edge of the network, consuming resources well before and after its use-phase, near future e-waste, increasing the need for bandwidth, increasing power consumption and the need to roll out more network infrastructure. Solving the problems caused by technology with technology, is that the circular economy?
Edge computing and working from home are no solution to environmental collapse, it simply shifts responsibility away from those corporations with the largest footprint. This shifting of responsibility away from corporations is an old strategy. It privatizes and centralizes (often once public) services, while outsourcing costs and responsibilities of care and maintenance. On a larger scale, it's classic capitalist extraction of value through the exploitation of free labour and resources, and in the context of this paper, it is also greenwashing. The oldest and most marked example I could find is the Keep America Beautiful campaign, started in the 1950 s by the disposable packaging industry in response to an attempt at introducing legislation to reduce waste. Disposable plastic packaging became more widely used at the same time as the rolling out of the US Interstate Highways System, resulting in a growing amount of roadside garbage. The campaign consisted of the launch of the concept of littering. Instead of attacking the problem of plastic waste by stopping the production of disposable packaging, the campaign placed the responsibility with consumers. "People start pollution. People can stop it." The campaign still exists. It's website states: "[c]reating a country where every community is a clean, green and beautiful place to live starts with people taking individual responsibility and collective action". Among the sponsors are many companies responsible for disposable plastic packaging and pollution - such as Pepsico, Dow Chemical Company, MacDonalds, Mars Wrigley and UPS - and their trade associations - the Plastics Industry Association, the International Bottled Water Association, the National Association of Convenience Stores and the American Chemistry Council. After 68 years of success, the campaign is still going, as seen in the images accompanying this paper. The strategy has become widely 


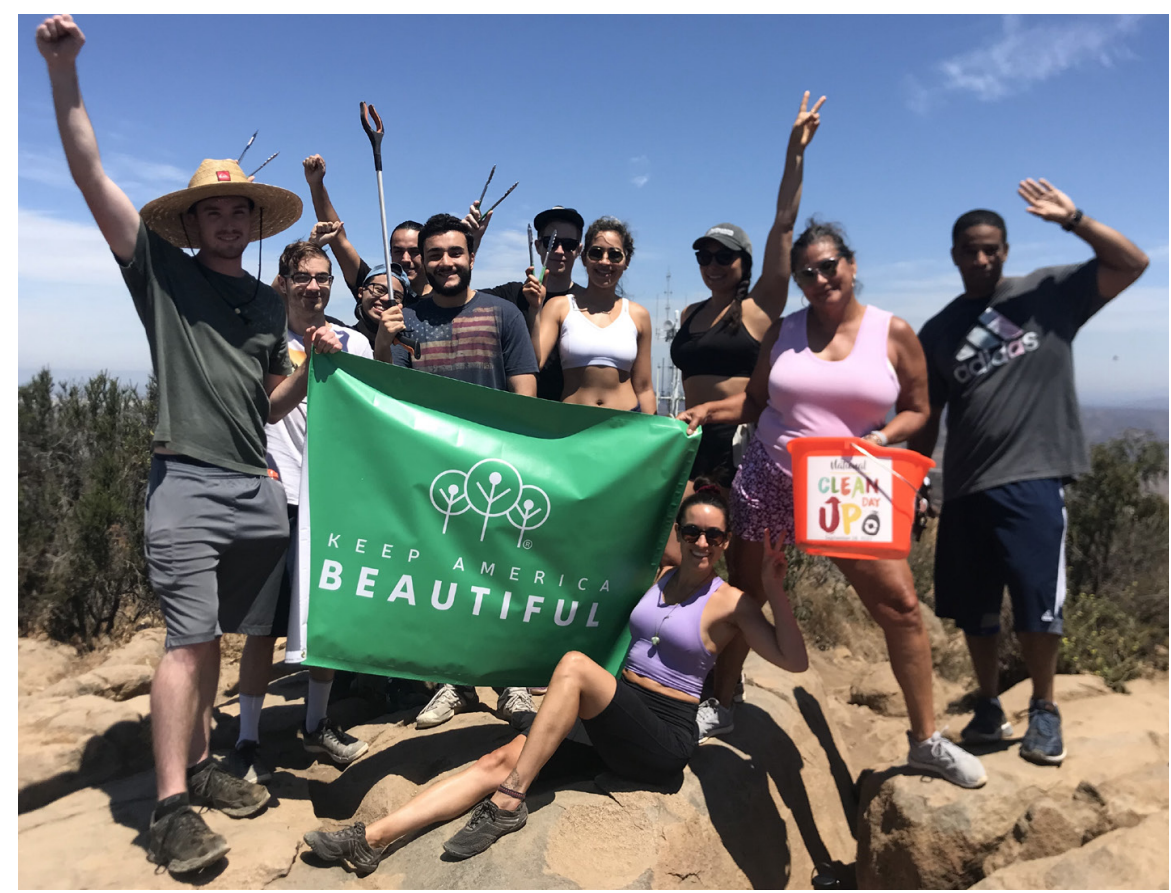

Figure 7: A group of enthusiastic Keep America Beautiful volunteers during a 2021 cleanup; Nelson, Ben, Cleanup group for Keep America Beautiful, 2021, Wikimedia, https:// commons.wikimedia.org/ wiki/File:Keep_America_ Beautiful_Cleanup_ Team.jpg.

used. We are still reaping the rewards, picking up after ourselves, updating our hardware, lowering the thermostat, hiding our messy office behind a virtual background.

Edge computing is promising endless streams of low latency game play and video streaming. It is promising to be useful for managing renewable energy, to be more energy efficient than data centres at the core and to reduce network traffic. On closer inspection, it is yet another example of capitalism profiting from the problems it creates, of neoliberal doctrine outsourcing burdens while privatizing once public, keeping centralised control over (once or again) decentralised infrastructures. Since the start of the pandemic the tech industry has seized the opportunity to profit from disaster and followed Airbnb into people's homes. Web 2.0 introduced a business strategy that, by giving access to the means of production of content, could gain ownership over and generate profit from the product (Carr). While edge computing and remote working, users have to also pay for access to and buy elements of the means of production, through the costs of electricity, hardware, heating and housing. As Jodi Dean puts it: "personal property becomes an instrument for the capital and data accumulation of the lords of platform". An escape is not easily imagined nor realised, as most people find themselves locked into Big Tech's platforms, relying on them for their livelihoods and social lives.

Can we still get rid of the almighty lords that have wedged themselves in between us and our work, between us and those we want to communicate with? Dean points out that current leftist dreams of small communities creating local commons, with a snarky mention of artisanal cheese, are in some sense elite. These dreams can only be realised by the few, are culturally specific and their localism expresses tendencies to, rather than resistance against, neofeudalism (ibid.). A refusal of the silent creep of appropriation of personal property through the imagining and building of communal, more sustainable computational infrastructures, however small, is a meaningful, although not unproblematic, form of resistance though. The free labour currently involved in small scale alternatives 
is unsustainable, only a true valuing of this work, both in financial as well as ethical terms is needed. Parallel to this refusal of digital enclosure, a refusal of individual responsibility for systemic problems such as climate change, is essential: holding those who lead harmful industries, and those governments aiding them, responsible through a demand for regulation. Rather than an escapist retreat, nourishing, alternative networks reimagine the infrastructures we depend on for organising collective action and refuse to put these in the hands of the lords of platform.

\section{Future research}

This paper is part of a larger interrogation of the links between Green Capitalism, Sustainable ICT and small-scale community practices, enmeshed with but trying to 'delink' from tech giants' monopolized infrastructures, motivated by ecological ethics. An initial lexicon of terminology associated with these practices is unpacked in the paper "A pluriverse of local worlds: a review of Computing within Limits related terminology and practices" (de Valk). Future research will expand this longitudinal review and in collaboration with The Photographers' Gallery will explore the diverse philosophies informing these practices.

\section{Works cited}

Alphabet. "CDP Climate Change Response 2020”. Google, Aug. 2020, p. 67, https:// www.gstatic.com/gumdrop/sustainability/alphabet-2020-cdp-climate-change-response. pdf.

Bresnihan, Patrick, and Patrick Brodie. "High-Energy Data Centres Not Quite as Clean and Green as They Seem". The Irish Times, 11 Sept. 2019, https://www. irishtimes.com/opinion/high-energy-datacentres-not-quite-as-clean-and-green-asthey-seem-1.4013992?mode=amp.

Carr, Nicholas. 2006. "Digital sharecropping", ROUGH TYPE.

Cook, Gary, and Elisabeth Jardim. "Clicking Clean Virginia”. Greenpeace, Feb. 2019, https://www.greenpeace.org/usa/reports/ click-clean-virginia/.

Dean, Jodi. 2020. "Neofeudalism: The End of Capitalism?", Los Angeles Review of Books. https://lareviewofbooks.org/article/ neofeudalism-the-end-of-capitalism/.

Donaghy, Tim, et al. "Oil in the Cloud: How Tech Companies Are Helping Big Oil Profit from Climate Destruction". Greenpeace, 19 May 2020, https://www.greenpeace.org/usa/ reports/oil-in-the-cloud/.

Engelsman, M. (no date). "How not to waste energy on 5G", TU Delft. https://www.tudelft.nl/en/stories/articles/ how-not-to-waste-energy-on- $5 \mathrm{~g} /$. 
Feldmann, Anja, et al. "The Lockdown Effect: Implications of the COVID-19 Pandemic on Internet Traffic". Proceedings of the ACM Internet Measurement Conference, ACM, 2020, pp. 1-18. doi:10.1145/3419394.3423658.

Fors, Per, and Thomas Lennerfors. "Translating Green IT: The Case of the Swedish Green IT Audit." ICT4S 2013: Proceedings of the First International Conference on Information and Communication Technologies for Sustainability, edited by Lorenz M. Hilty, Bernard Aebischer, Göran Andersson and Wolfgang Lohmann, ETH Zurich, 2013, pp. 208-16, doi:http://dx.doi.org/10.3929/ ethz-a-007337628.

Gabrys, Jennifer. 2014. "Powering the Digital: From Energy Ecologies to Electronic Environmentalism". Media and the Ecological Crisis, edited by Richard Maxwell, Jon Raundalen and Nina Lager Vestberg. New York and London: Routledge, pp. 3-18.

Global Action Plan. "Green ICT Handbook: A Guide to Green ICT". Global Action Plan, 2009.

Google. "A Circular Google". Google, June 2019. https://www.gstatic.com/gumdrop/ sustainability/circular-google.pdf.

Google. "Google Environmental Report 2020". Google, 2020, https://www. gstatic.com/gumdrop/sustainability/google2020-environmental-report.pdf.

Intergovernmental Platform on Biodiversity and Ecosystem Services (IPBES).

"Workshop Report on Biodiversity and Pandemics". pp. 2-3. IPBES secretariat, 29 Oct. 2020. doi:10.5281/ZENODO.4147317.
Koningstein, Ross, and David Fork. "What It Would Really Take to Reverse Climate Change". IEEE Spectrum: Technology, Engineering, and Science News, 18 Nov. 2014, https://spectrum.ieee.org/energy/ renewables/what-it-would-really-take-toreverse-climate-change.

“Keep America Beautiful”. Keep America Beautiful, 2020, https://kab.org/.

Klein, Naomi. This Changes Everything: Capitalism vs The Climate. Simon \& Schuster, 2014.

Lennerfors, Thomas Taro, et al. "ICT and Environmental Sustainability in a Changing Society: The View of Ecological World Systems Theory". Information Technology \& People, edited by Dr David Kreps and Dr Kai Kimppa, vol. 28, no. 4, Nov. 2015, pp. 758-74. doi:10.1108/ITP-09-2014-0219.

Lin, Halden, et al. "The Hidden Cost of Digital Consumption”. Parametric Press, 19 Oct. 2020, https://parametric.press/issue-02/ streaming/. doi: 10.5281/zenodo.4105556

Majima, Takashi, et al. "Green IT Did Not Take Place". Journal of Japan Society for Information Management, vol. 37, no. 2, 2017, pp. 81-96. doi:10.20627/ jsim.37.2_81.

Mingay, Simon. "Green IT: The New Industry Shock Wave”. Gartner, 2007.

Preist, Chris, et al. 'Evaluating Sustainable Interaction Design of Digital Services: The Case of YouTube'. Proceedings of the $2019 \mathrm{CHI}$ Conference on Human Factors in Computing Systems, ACM, 2019, pp. 1-12. DOI.org (Crossref), doi:10.1145/3290605.3300627. 
de Valk, Marloes. 2021. "A pluriverse of local worlds: a review of Computing within Limits related terminology and practices". LIMITS '21: Workshop on Computing within Limits, June 14-15, 2021.

Weerwind, Frank, and Stijn Steenbakkers. "Ruimtelijke Strategie Datacenters". Ministery of the Interior and Kingdom relations, 2019, pp. 1-35, https://www. rijksoverheid.nl/documenten/rapporten/2019/03/15/ ruimtelijke-strategie-datacenters.

Wright, Christopher, and Daniel Nyberg.

Climate Change, Capitalism and Corporations: Processes of Creative SelfDestruction. Cambridge University Press, 2015.

Zhou, Zhi, et al. "Edge Intelligence: Paving the Last Mile of Artificial Intelligence with Edge Computing". Proceedings of the IEEE, vol. 107, no. 8, Aug. 2019, pp. 1738-62. doi:10.1109/JPROC.2019.2918951. 